\title{
A Case of Henoch-Schönlein Purpura with Fulminant Complications and Its Long-term Outcome
}

\author{
Dong Hyun Lee, M.D. ${ }^{1}$ \\ Eun-So LEE, M.D., Ph.D. ${ }^{2}$ \\ Jeong Hong, M.D., Ph.D. ${ }^{3}$ \\ Kwang-Hwa Park, M.D., Ph.D. ${ }^{4}$ \\ Ki Soo Pai, M.D., Ph.D. ${ }^{1}$ \\ Department of Pediatrics', Ajou \\ University School of Medicine, Suwon, \\ Korea, Department of Dermatology², \\ Ajou University School of Medicine, \\ Suwon, Korea, Department of Pediatric \\ Surgery ${ }^{3}$, Ajou University School of \\ Medicine, Suwon, Korea, Department \\ of Pathology ${ }^{4}$, Yonsei University Wonju \\ College of Medicine, Wonju, Republic \\ of Korea
}

\section{Corresponding author:}

Ki Soo Pai, M.D., Ph.D.

Department of Pediatrics, Ajou University

School of Medicine 164 Worldcup-ro,

Yeongtong-gu, Suwon 16499, Korea

Tel: +82-31-219-5160

Fax: +82-31-219-5169

E-mail:kisoopai@ajou.ac.kr

Received: 2 October 2019

Revised: 21 October 2019

Accepted: 23 October 2019
Henoch-Schönlein purpura (HSP) is a systemic vasculitis characterized by purpura, arthritis, abdominal pain, and nephritis. Gastrointestinal involvement can manifest as pain, intussusception, intestinal bleeding, and intestinal perforation. We report a case of fulminant HSP at an age of eight in 1994, with multiple complications of intra-thoracic bleeding, massive intestinal perforation, nephritis, and various skin rashes. The brisk bleeding findings of intestinal on Technetium-99m-labeled red blood cell scan ( ${ }^{99 m} \mathrm{Tc}$ RBC scan) were well matched to those of the emergency laparotomy and the resected intestine. The patient's abdominal conditions improved gradually but nodular skin eruptions developed newly apart from improving preexisting lower limb rashes and the urine findings continued abnormal, so skin and kidney biopsy were done for the diagnosis. After cyclosporine therapy, skin eruptions and urine findings returned to normal gradually. On a follow-up after 25 years in 2019, the patient is 33-year-old, healthy without any abnormality on blood chemistries and urine examination.

Key words: HSP, Intestinal perforation, Nephritis, Pleural hemorrhage

\section{Introduction}

Henoch-Schönlein purpura (HSP) is the most common form of systemic vasculitis in children characterized by non-thrombocytopenic purpura, arthritis, abdominal pain, and nephritis ${ }^{1}$. Gastrointestinal involvement is present in two-thirds of patients, which may be due to gastrointestinal wall edema and submucosal hemorrhage ${ }^{2)}$. Abdominal pain is a common symptom and can lead to serious complications such as intussusception, intestinal bleeding, and intestinal perforation ${ }^{3)}$, where early diagnosis and treatment are important. Although HSP is common disease in children, there are few reports of cases with multiple complications at the same time. This case may provide useful information for clinicians to assess the serious conditions in patients with HSP for the earlier diagnosis and treatment.

\section{Case report}

An 8-year-old male patient visited the emergency department in 1994, with skin rashes on both legs, abdominal pain, and arthralgia occurred 4 days ago. 
He received conservative treatment at a local clinic for 2 days but showed no improvement. The patient had neither recent medical history nor family history of HSP. Vital signs were measured as: blood pressure, 100/60 mmHg; pulse rate, 92 beats/min; respiratory rate, $22 / \mathrm{min}$; and body temperature, $37.0^{\circ} \mathrm{C}$. On physical examination, bilateral tonsillar enlargements, numerous palpable purpura in both legs and buttocks, and knee joint tenderness and abdominal tenderness were noted, but there was no rebound tenderness.

The laboratory test revealed the following results: white blood cell count, $13,300 / \mathrm{mm}^{3}$; hemoglobin, $13.3 \mathrm{~g} / \mathrm{dL}$; platelet count, $372,000 / \mathrm{mm}^{3}$; erythrocyte sedimentation rate, $18 \mathrm{~mm} / \mathrm{hr}$; serum total protein, $5.7 \mathrm{~g} / \mathrm{dL}$; albumin, $3.4 \mathrm{~g} / \mathrm{dL}$; blood urea nitrogen(BUN), $15.1 \mathrm{mg} / \mathrm{dL}$; creatinine, $0.9 \mathrm{mg} /$ $\mathrm{dL}$; C-reactive protein, $1.2 \mathrm{mg} / \mathrm{dL}$; antistreptolysin O (ASO), 1,317 IU/mL; prothrombin time, 12.8 seconds; and activated partial thromboplastin time, 27 seconds. Urinalysis showed $1+$ protein and $2+$ blood. Creatinine clearance $(\mathrm{Ccr})$ calculated through a 24-hour urine collection was 145.3 $\mathrm{ml} / \mathrm{min} / 1.73 \mathrm{~m}^{2}$.

The patient was diagnosed with HSP and treated with intravenous dexamethasone $(0.1 \mathrm{mg} / \mathrm{kg}$ per dose every 6 hours) from the $1^{\text {st }}$ day of hospitalization. The patient's conditions were stable with intermittent abdominal pains for the $1^{\text {st }}$ week of hospitalization. On the $8^{\text {th }}$ day of hospitalization, he developed a sudden severe abdominal pain with the expansion of purpura on both legs and feet including buttocks, and abdominal ultrasonography showed extensive small intestinal wall thickenings and minimal ascites (Fig. 1). On the 10th day of hospitalization, patient's abdominal pain and bloody diarrhea worsened, but no sub-dia-

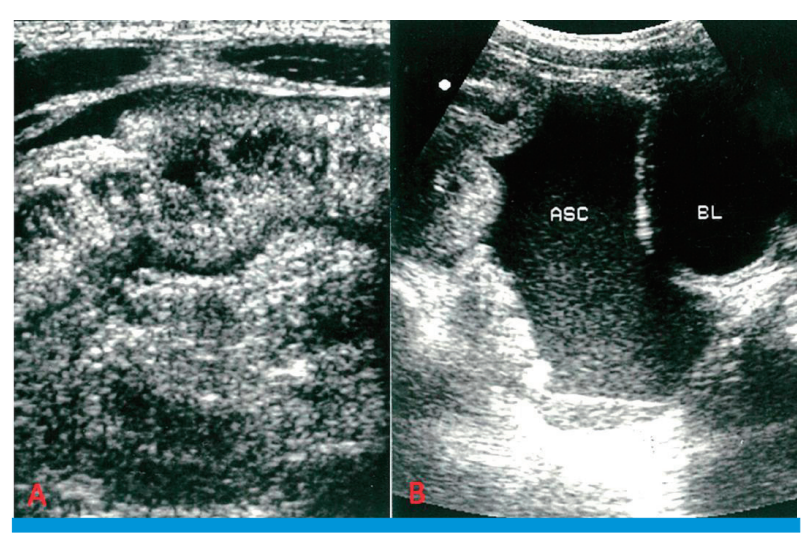

Fig. 1. Abdominal ultrasonography shows thickened bowel wall and edema (A), and dilated bowel loops with fluid collection (B), on the $8^{\text {th }}$ hospital day. phragmatic air was found on simple X-ray. On the same day, Technetium-99m-labeled red blood cell scan $\left({ }^{99 \mathrm{~m}} \mathrm{Tc}-\mathrm{RBC}\right.$ scan) revealed diffuse intramural and intraluminal hemorrhages, but no extraluminal bleeding to abdominal cavity (Fig. 2). On the $12^{\text {th }}$ day of hospitalization, abdominal distension developed and serum hemoglobin decreased from $11.6 \mathrm{~g} / \mathrm{dL}$ to $9.2 \mathrm{~g} / \mathrm{dL}$. Under the suspicion of intestinal perforation, paracentesis was performed and $150 \mathrm{cc}$ of serosanguinous fluid was drained to confirm hemoperitoneum.

On the $13^{\text {th }}$ day of hospitalization, the patient complained of dyspnea. Pleural effusion was found on chest X-ray, and chest tube drained $200 \mathrm{~mL}$ of bloody fluid. Direct and rebound tenderness were present on the entire abdomen area, and bilateral sub-diaphragmatic free air was detected on simple X-ray (Fig. 3). The patient was referred to pediatric surgery and emergency laparotomy was done to reveal a large amount of pus collection in the peritoneal cavity. Multiple linear perforations were noted along the antimesenteric border at the $25 \mathrm{~cm}$ proximal portion of ileum from the ileocecal valve. About $50 \mathrm{~cm}$ of small intestine was necrotized, and segmental resection was performed to reveal hemorrhagic patches on the intestinal membrane and ischemic necrosis (Fig. 4). In the mesentery, multiple small arterial hemorrhagic points were noted which might have contributed to intestinal necrosis and perforation.

After the operation, the patient received intravenous antibiotics for 2 weeks and then the skipped dexamethasone was restarted as oral prednisolone $(1 \mathrm{mg} / \mathrm{kg} /$ day divided into 3 doses). The patient tolerated well and recovered gradually, despite persistent purpuras, intermittent abdominal

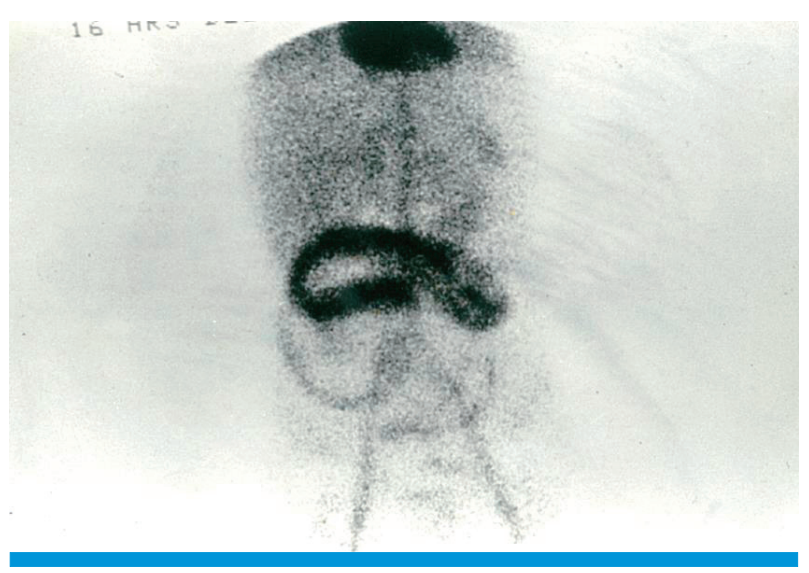

Fig. $2 .{ }^{99 \mathrm{~m}} \mathrm{Tc}$-labeled RBC scan shows wide range small intestinal bleeding with intraluminal and intramural nature on the $10^{\text {th }}$ hospital day. 


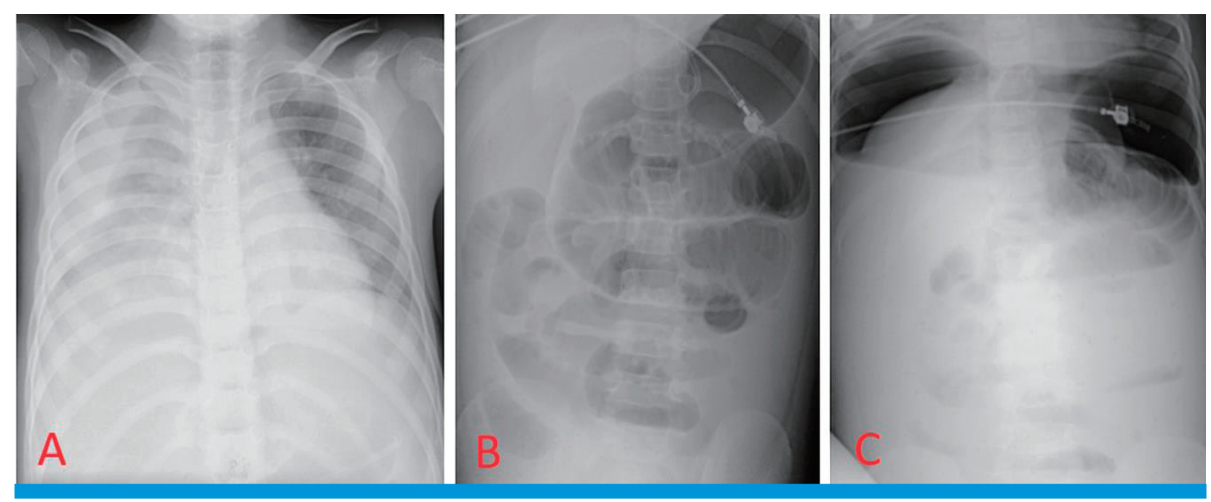

Fig. 3. Simple X-ray views showing pleural effusion on the right lung filed on $13^{\text {th }}$ hospital day (A), dilated bowel loops on $12^{\text {th }}$ hospital day (B), and the presence of sub-diaphragmatic free air on the $13^{\text {th }}$ hospital day $(C)$.

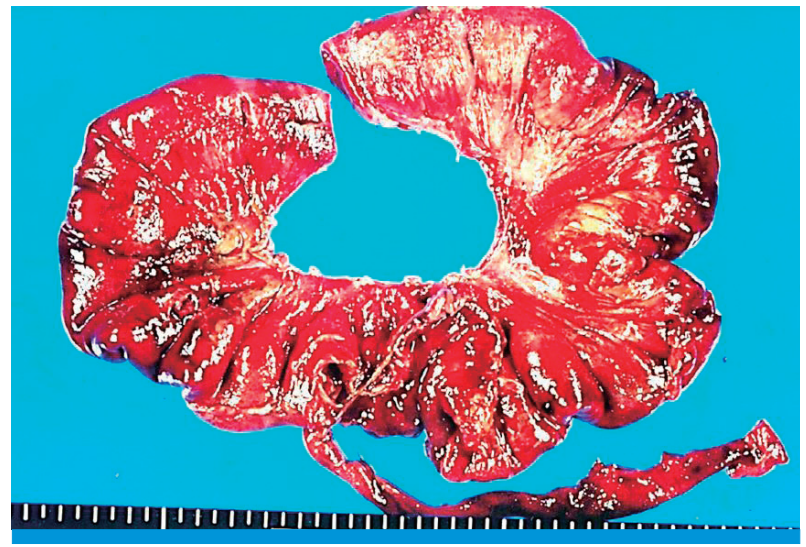

Fig. 4. Gross appearance of the resected intestine on the $13^{\text {th }}$ hospital day, revealed $25 \mathrm{~cm}$ linear rupture of bowel wall due to necrosis at the anti-mesenteric border.

pains and urinary abnormalities. The patient was discharged on the $28^{\text {th }}$ postoperative day.

One month after discharge, new itching nodular skin rashes on extensor surface of hands, fingers, and elbows began to develop and became more severe and skin biopsy of the hand lesion on $56^{\text {th }}$ day of discharge, revealed leukoclastic vasculitis (Fig. 5).

Urinary abnormality, microscopic hematuria (5-30 RBC/ $\mathrm{HPF}$ ) and proteinuria (30-100 $\mathrm{mg} / \mathrm{dL})$ continued for 2 months after the discharge despite oral prednisolone and angiotensin-converting enzyme inhibitors (ACEis) medications, and kidney biopsy on the $62^{\text {nd }}$ discharge day revealed mesangial cell proliferation, and increase in mesangial matrix with immunoglobulin A deposition on immunofluorescence study (Fig. 6). Cyclosporine ( $5 \mathrm{mg} / \mathrm{kg} /$ day oral in two divided doses) and ACEi ( $5 \mathrm{mg}$ daily) were given for 12 months. Proteinuria resolved after 6 months of treat-

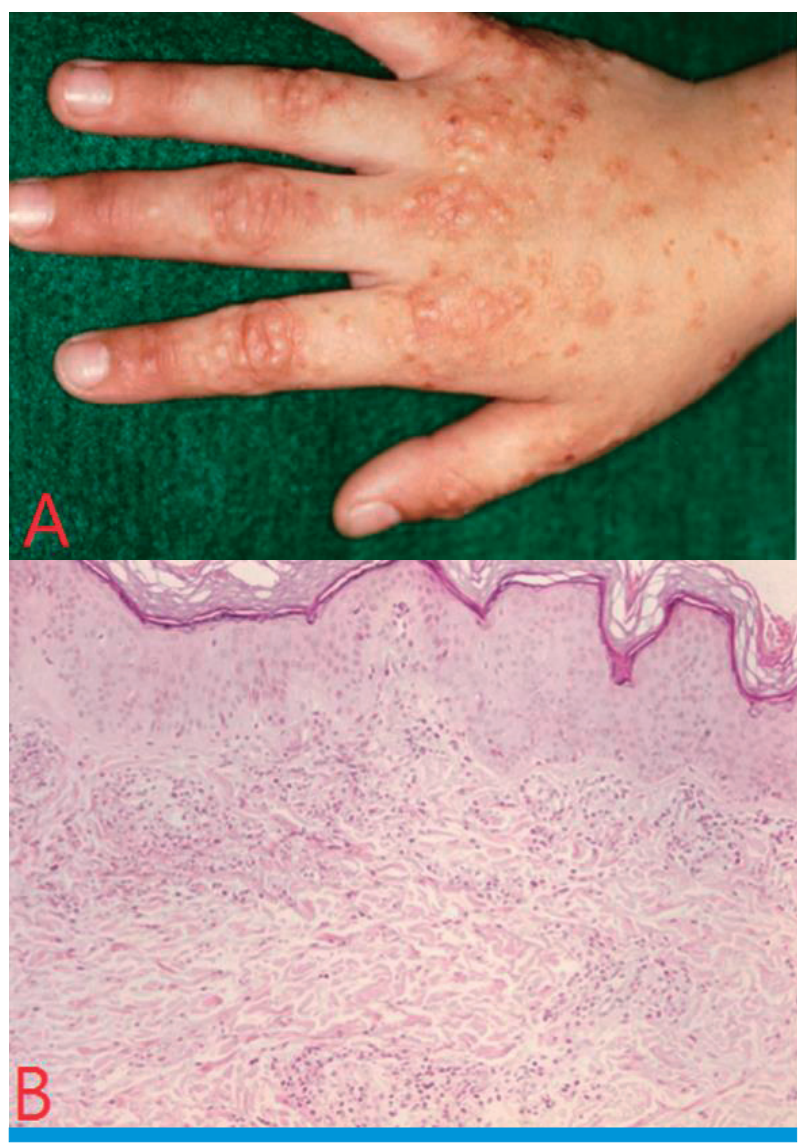

Fig. 5. Nodular skin lesions on the dorsum of hand and finger (A), and the skin biopsy on the $88^{\text {th }}$ day of disease onset (B) (H\&E stain $\mathrm{X} 100)$.

ment, and hematuria, after 2 years.

And on the follow-up after 25 years, the patient visited our hospital for medical check-up at the age of 33 years old. After examinations, he showed normal physical and renal status without any gastrointestinal signs; height $179 \mathrm{~cm}$, body weight $72 \mathrm{~kg}$, BUN $24.4 \mathrm{mg} / \mathrm{dL}$, serum creatinine 1.20 
$\mathrm{mg} / \mathrm{dL}$, and CCr $108 \mathrm{ml} / \mathrm{min} / 1.73 \mathrm{~m}^{2}$ by 24 -hour urine collection, and there was no urine abnormality.

\section{Discussion}

HSP is a systemic vasculitis caused by IgA-containing immune complexes depositing in small vessel walls, such as arterioles and venules, which activates the complement system $^{1)}$. It is known that HSP occurs in 20 cases per 100,000 children annually, and found twice as many in males than females ${ }^{4}$. Peak age incidence is 4-6 years, but can occur in all age groups ${ }^{4,8)}$. Upper respiratory infection such as streptococcus, staphylococcus, and parainfluenza or vaccination, medication such as antibiotics, and autoimmune disease are often preceded ${ }^{6)}$. In this patient, serum ASO level increased to $1,315 \mathrm{IU} / \mathrm{mL}$ with tonsillar hypertrophy, suggesting a precedence of streptococcal infection.

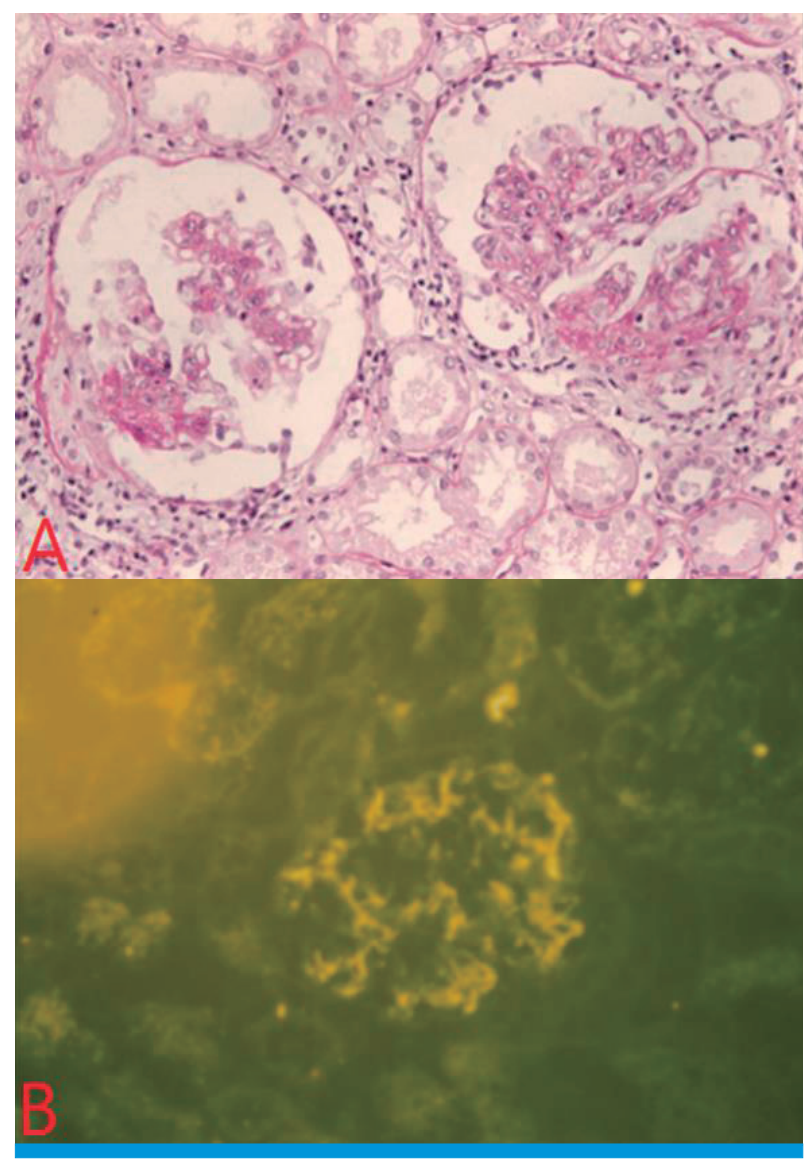

Fig. 6. Renal biopsy findings on the $90^{\text {th }}$ day of disease onset shows segmental mesangial proliferation (A, periodic acid-schiff stain, $\times 400)$ and prominent immunoglobulin A deposit in mesangium (B, Immunofluorescence stain. $\times 400)$.
European League Against Rheumatism/Pediatric Rheumatology European Society (EULAR/PReS) defined the diagnostic criteria of HSP as follows: palpable purpura in the presence of at least one of the following four feature: diffuse abdominal pain, arthritis or arthralgia, any biopsy showing predominant IgA deposition, and renal involvement (any hematuria and/or proteinuria) ${ }^{5}$. Skin involvement is the most common manifestations of all HSP patients $^{1,7)}$. Petechiae and palpable purpura are common forms, but it may appear as erythema, bullous, or nodular lesions ${ }^{7}$. It is characteristically distributing mainly on bilateral lower limbs but may also appear in areas such as face, ears, and hands ${ }^{7}$. In our case, nodular skin lesions appeared newly on the dorsum of the hands and elbows two months after the onset of the disease. On the $84^{\text {th }}$ day of disease onset, skin biopsy was done and showed leukoclastic vasculitis.

Renal involvement is considered upon presence of hematuria ${ }^{1)}$. Proteinuria is very rarely found alone without hematuria ${ }^{1)}$. Nephritis develops within 3 months of skin manifestations and mostly resolves within 1 year, but consistent hematuria and proteinuria may progress to end-stage renal disease $(\mathrm{ESRD})^{7}$. Renal involvement is the most crucial prognostic factor in $\mathrm{HSP}^{9)}$. In this patient, both hematuria and proteinuria occurred from the beginning of HSP and persisted more than three months. Proteinuria resolved after 6 months of cyclosporine therapy, and hematuria disappeared completely after 2 years.

Gastrointestinal involvement occurs in $50-75 \%$ of HSP patients and in 10-30\%, it may precede the skin lesions ${ }^{2}$. Symptoms such as abdominal pain, vomiting, hematemesis, and hematochezia can be found ${ }^{2}$. Abdominal pain is the most common symptom and it may be colicky ${ }^{7,9,11}$. It rarely accompanies tenderness or rebound tenderness and mostly improves within a few days with conservative treatment ${ }^{2}$. If abdominal pain persists with abdominal distension or vomiting, close observation should be made to distinguish from intussusception, acute appendicitis, intestinal obstruction or perforation ${ }^{11}$.

Intestinal perforation is a rare complication of HSP. It occurs mainly in the small intestine, but some cases where multiple perforations involve stomach and duodenum have been reported ${ }^{2}$. It is due to ulceration by vasculitis and consequent ischemic changes and necrosis in the bowel wall ${ }^{22}$.

It is known that severe abdominal manifestations may 
increase the risk of renal damage in HSP patients ${ }^{12)}$. We also had experienced such a case ${ }^{13)}$ before, but to the contrary, this patient resulted in normal renal function and normal urine findings on the follow-up examinations after 25 years.

HSP improves simply by conservative management in most cases but the treatment of HSP still remains controversial $^{10,14)}$. The nationwide study reported $56.6 \%$ of children with HSP were prescribed steroids in Korea ${ }^{10)}$. The recent Cochrane review concluded that there is no evidence of benefit for the use of steroid to prevent kidney disease in children with $\mathrm{HSP}^{14)}$. But Jauhola et al. reported prednisone treatment reduced the severity of abdominal or joint pain and also the durations of abdominal pain ${ }^{15)}$. In this case, despite steroid treatment the gastrointestinal symptoms became more severe and led to intestinal necrosis and perforation, requiring surgical resection of small bowel on the $13^{\text {th }}$ day of hospitalization (Fig. 4).

Pulmonary hemorrhage is an unusual complication of $\mathrm{HSP}^{16)}$. A systematic review reported the prevalence of pulmonary complication ranged $0.8 \%$ to $5 \%$, including hemoptysis, dyspnea, and chest infiltration ${ }^{16)}$. In this case, the patient complained dyspnea and showed pleural fluid collection on the right side and chest tube drainage revealed serosanguinous pleural effusion, suggesting bleeding from pleural cavity (Fig. 3).

In conclusion, we report a case of HSP with multiple complications such as intestinal perforation, pulmonary hemorrhage and various skin rashes, nephritis and its longterm outcome.

\section{Conflicts of interest}

The authors declare that there is no conflict of interest.

\section{ORCID iDs}

Dong Hyun Lee: https://orcid.org/0000-0002-0648-3408 Eun-So LEE: https://orcid.org/0000-0003-0232-7704 Jeong Hong: https://orcid.org/0000-0002-8101-7511 Kwang-Hwa Park: https://orcid.org/0000-0003-2197-152X Ki Soo Pai: https://orcid.org/0000-0003-0373-4336

\section{Patient consent}

This study was approved by the institutional review board (IRB), and the consent was waived due to the nature of the retrospective study (IRB number MED-EXP-19-385)

\section{References}

1. Trnka P. Henoch-Schönlein purpura in children. J Paediatr Child Health 2013;49:995-1003.

2. Choong CK, Beasley SW. Intra-abdominal manifestations of Henoch-Schönlein purpura. J Paediatr Child Health 1998;34: 405-9.

3. Lerkvaleekul B, Treepongkaruna S, Saisawat P, Thanachatchairattana P, Angkathunyakul N, Ruangwattanapaisarn N, et al. HenochSchönlein purpura from vasculitis to intestinal perforation: a case report and literature review. World J Gastroenterol 2016;22:608994.

4. Gardner-Medwin JM, Dolezalova P, Cummins C, Southwood TR. Incidence of Henoch-Schönlein purpura, Kawasaki disease, and rare vasculitides in children of different ethnic origins. Lancet 2002;360:1197-202.

5. Ozen S, Ruperto N, Dillon MJ, Bagga A, Barron K, Davin JC, et al. EULAR/PReS endorsed consensus criteria for the classification of childhood vasculitides. Ann Rheum Dis 2006;65:936-41.

6. Weiss PF, Klink AJ, Luan X, Feudtner C. Temporal association of streptococcus, staphylococcus, and parainfluenza pediatric hospitalizations and hospitalized cases of Henoch-Schönlein purpura. J Rheumatol 2010;37:2587-94.

7. Trapani S, Micheli A, Grisolia F, Resti M, Chiappini E, Falcini F, et al. Henoch-Schönlein purpura in childhood: epidemiological and clinical analysis of 150 cases over a 5-year period and review of literature. Semin Arthritis Rheum 2005;35:143-53.

8. Saulsbury FT. Henoch-Schönlein purpura in children. Report of 100 patients and review of the literature. Medicine (Baltimore) 1999;78:395-409.

9. Pabunruang W, Treepongkaruna S, Tangnararatchakit K, Chunharas A, Phuapradit P. Henoch-Schönlein purpura: clinical manifestations and long-term outcomes in Thai children. J Med Assoc Thai 2002;85:S1213-8.

10. Shim JO, Han K, Park S, Kim GH, Ko JS, Chung JY. Ten-year Nationwide Populationbased Survey on the Characteristics of Children with Henoch-Schönlein Purpura in Korea. J. Korean Med Sci 2018;33:1-10.

11. Katz S, Borst M, Seekri I, Grosfeld JL. Surgical evaluation of HenochSchönlein purpura. Experience with 110 children. Arch Surg 1991;126:849-53; discussion 53-4.

12. Kaku Y, Nohara K, Honda S. Renal involvement in Henoch-Schönlein purpura: a multivariate analysis of prognostic factors. Kidney 
www.chikd.org

Int 1998:53:1755-9.

13. Seo MK, Hong J, Yim HE, Pai KS. A Patient with Henoch-Schönlein Purpura with Intussusception and intractable Nephritis. Child Kidney Dis 2016;20:92-6.

14. Hahn D, Hodson EM, Willis NS, Craig JC. Interventions for preventing and treating kidney disease in Henoch-Schönlein Purpura (HSP). Cochrane Database Syst Rev 2015;(8):CD005128.
Lee DH, et al. • A Fulminant HSP and its Long-term Outcome 133

15. Jauhola O, Ronkainen J, Koskimies O, Ala-Houhala M, Arikoski P, Hölttä T, Jahnukainen T, Rajantie J, Ormälä T, Nuutinen M. Clinical course of extrarenal symptoms in Henoch-Schonlein purpura: a 6-month prospective study. Arch Dis Child 2010;95:871-6.

16. Rajagopala S, Shobha V, Devaraj U, D'Souza G, Garg I. Pulmonary hemorrhage in Henoch-Schönlein purpura: case report and systematic review of the english literature. Semin Arthritis Rheum 2013:42:391-400. 